\title{
Eskişehir'de Doğal Alanlardan Toplanan Otlak Ayrığında (Agropyron cristatum L. Gaertn.) Islah Yönünden Önem Taşıyan Özelliklerin Belirlenmesi
}

\author{
*ilker ERDOĞDU \\ A. Kadir ATALAY \\ A. Levent SEVER \\ Geçit Kuşağı Tarımsal Araştırma Enstitüsü, Eskişehir \\ *Sorumlu yazar e-posta (Corresponding author e-mail): ilkererdogdu1@hotmail.com
}

Öz

2010-2012 arasında Eskişehir'de yürütülen araştırmanın amacı, Orta Anadolu ve benzeri ekolojilerde yürütülen mera ıslah çalışmalarında kullanılabilecek yeni çeşitlerin geliştirilmesi çalışmalarına materyal ve bilgi üretmektir. Çalışmada toplanan tohumların bir kısmı durak bilgileri ile birlikte Ankara ve İzmir'deki Gen Bankalarına gönderilmiş, kalan kısmı serada fide haline getirildikten sonra araziye aktarılmıştır. 2012 yılında toplam 38 populasyon gözlem ve ölçümlere tabi tutularak, bir anlamda karakterize edilmişlerdir. Daha sonra verilerin ortalama ve standart hata değerleri saptanmıştır. Populasyon ortalama değerleri ana sap uzunluğunda 38.5-68.4 cm, ana sap kalınlığında 1.1-3.0 mm, bayrak yaprak boyu 3.9-9.6 cm, bayrak yaprak eni 2.2-5.1 mm, ana saptaki boğum arası uzunluğu 7.8-18 cm, ana saptaki boğum sayısı 2.9-4.2 adet, büyüme şekli 6.2-8.8, kışa dayanıklılık 5.1-8.0 ve kardeşlenme potansiyeli 5.2-8.0 arasında değişmiştir. Özellikler arasındaki ilişkileri belirlemek amacıyla yapılan korelasyon analizi sonucuna göre, ana sap kalınlığı, bayrak yaprak eni ve bayrak yaprak boyu ile kardeşlenme potansiyeli arasındaki olumlu ilişkiler $\left(r=0.472^{* *}\right.$, $r=0.456^{* *}$ ve $\left.r=0.453^{* *}\right)$ ve bayrak yaprak eni ile kışa dayanıklılık arasındaki negatif ilişki $\left(r=0.379^{* *}\right)$ dikkat çekmiştir.

Anahtar Kelimeler: Otlak ayrığı, ıslah, gen bankası, korelasyon

\section{Determination of Important Characteristics of Crested Wheatgrass (Agropyron cristatum L. Gaertn.) Populations Collected from Natural Areas for Breeding Purposes in Eskişehir}

\begin{abstract}
The aim of the research conducted between 2010-2012 in Eskişehir is obtaining material and information for breeding of new varieties which can be used in rangeland improvement activities in Central Anatolia and alike regions. Some of the collected seeds were send with passport information to the Gene Banks in Ankara and İzmir. The rest of the seeds were grown in greenhouse and then transfered into field. In 2012, 38 populations were identified observing and measuring some characteristics. Then, mean and standart error values of the obtained data were determined. The mean values of the populations in main stem length, main stem thickness, flag leaf length, flag leaf width, internode length, number of nodes, growth pattern, winter resistance and tillering capacity were changed between 38.5-68.4 cm, 1.1-3.0 mm, 3.9-9.6 cm, 2.2-5.1 mm, $7.8-18 \mathrm{~cm}, 2.9-4.2,6.2-8.8,5.1-8.0$, and 5.2-8.0, respectively. According to the correlation analysis to determine relationships between the characteristics, there were positively correlations between tillering capacity and main stem thickness $\left(r=0.472^{* *}\right)$, tillering capacity and flag leaf length $\left(r=0.456^{* *}\right)$ and tillering capacity and flag leaf width $\left(r=0.453^{* *}\right)$. A negative correlation between winter resistance and flag leaf width $\left(r=0.379^{* *}\right)$ was also remarkable.
\end{abstract}

Keywords: Crested wheatgrass, collection, breeding, gene bank, correlation 


\section{Giriş}

U Ikemiz doğal florası buğdaygil yem bitkileri bakımından oldukça zengin olmasına rağmen suni mera tesisi ve üstten tohumlama çalışmalarında çoğunlukla yurt dışından ithal edilen çeşitler kullanılmaktadır ve bu çeşitlerin ülkemizin farklı ekolojik şartlarına uyumu konusunda sorunlar yaşanmaktadır (Oral ve Açıkgöz 2002). Bu nedenle farklı bölgelerimizden bu türlerin toplanması ve ıslah materyali olarak kullanılma olanaklarının araştırılması ülkemiz için önemli bir konudur. Orta Anadolu meralarının doğal bitkilerinden olan otlak ayrığı ilkbaharda erken büyümeye başlayan ve ot verimi oldukça yüksek bir buğdaygil türüdür. Bitki çok uzun ömürlü olup kışa ve kurağa dayanıklıdır (Serin ve ark. 1998). Genelde otlatılarak değerlendirilen ve rejenerasyon yeteneği de oldukça yüksek olan tür kurak meralarda yürütülen suni mera tesisi ve üstten tohumlama çalışmaları için idealdir. Bu çalışmada, Eskişehir ve benzeri ekolojilerde yürütülen mera ıslah çalışmalarında kullanılabilecek çeşitlerin ıslahında kullanılmak üzere doğal alanlardan toplanan otlak ayrığında (Agropyron cristatum) yürütülen bazı gözlem ve ölçüm sonuçlarına yer verilmiştir. İncelenen bu özelliklerin aralarındaki ilişkilerde korelasyon analizine tabi tutulmuştur. Kavuncu ve ark. (1985) korelasyonun iki değişken arasındaki doğrusal ilişkinin bir ölçütü olduğunu bildirmektedir. Bu çalışmada özellikle kardeşlenme potansiyeli ile diğer parametreler arasındaki ilişkiler üzerinde durulmuştur. Tüm bu çalışmalarla Geçit Kuşağı Tarımsal Araştırma
Enstitüsü'nde başlayan çeşit geliştirme çalışmalarında kullanılmak üzere materyal ve bilgi üretilmiştir.

\section{Materyal ve Yöntem}

Çalışmalar 2010, 2011 ve 2012 yıllarında Eskişehir İlinde yürütülmüştür. Eskişehir iklim verileri aşağıdaki çizelgede özetlenmiştir (Çizelge 1). İlde uzun yıllar yıllık toplam yağış miktarı 347 $\mathrm{mm}$ ve ortalama sıcaklık ise $10.8^{\circ} \mathrm{C}$ 'dir. Çalışmaların yürütüldüğü yıllarda toplam yağış uzun yıllar ortalamasından yüksektir. 2010, 2011 ve 2012 yıllarında yıllık ortalama sıcaklık değerleri de uzun yıllar ortalamasına göre yüksek gerçekleşmiştir. Plantasyonun kurulduğu alandan alınan toprak örneklerine ait analiz sonuçlarına göre deneme yerinin toprağı; hafif alkali, killi, orta kireçli, hafif tuzlu, potasyumca zengin, fosfor bakımından zengindir (Çizelge 2). 2010 yılında gerçekleştirilen toplama çalışmasında rakım ve yöneyler dikkate alınarak 10-15 km'de bir olacak şekilde belirlenen duraklardan tek bitki tohumları alınmıştır (Alan 1986).

Ayrıca bu bitkilerin yoğun olarak bulunduğu köy mezarlıkları gibi korunaklı alanlarda da toplama yapılmıştır. Çalışma sırasında toprak tipi, eğimi, görünüşü, su rejimi ve bunların bitki örtüsü ile ilişkisi gibi ekolojik faktörlerde göz önünde bulundurulmuş, bitkinin genel görünüşü (dik, yatık gibi), rengi ve bitki boyu gibi özelliklere göre de seçim yapılmıştır.

Çizelge 1. Eskişehir ili iklim verileri

Table 1. Meteorological data of Eskişehir province

\begin{tabular}{cccccccccc}
\hline & \multicolumn{3}{c}{2010} & \multicolumn{3}{c}{2011} & & & 2012 \\
Aylar & $\begin{array}{c}\text { Toplam } \\
\text { Yağış } \\
(\mathrm{mm})\end{array}$ & $\begin{array}{c}\text { Ort. } \\
\text { Sıc. } \\
\left(\mathrm{C}^{\circ}\right)\end{array}$ & $\begin{array}{c}\text { Ort. } \\
\text { Nem } \\
(\%)\end{array}$ & $\begin{array}{c}\text { Toplam } \\
\text { Yağış } \\
(\mathrm{mm})\end{array}$ & $\begin{array}{c}\text { Ort. } \\
\text { Sıc. } \\
\left(\mathrm{C}^{\circ}\right)\end{array}$ & $\begin{array}{c}\text { Ort. } \\
\text { Nem } \\
(\%)\end{array}$ & $\begin{array}{c}\text { Toplam } \\
\text { Yağış } \\
(\mathrm{mm})\end{array}$ & $\begin{array}{c}\text { Ort. } \\
\text { Sıc. } \\
\left(\mathrm{C}^{\circ}\right)\end{array}$ & $\begin{array}{c}\text { Ort. } \\
\text { Nem } \\
(\%)\end{array}$ \\
\hline Ocak & 36.0 & 1.5 & 95.2 & 26.6 & 0.3 & 97.0 & 58.0 & -3.6 & 96.8 \\
Şubat & 42.6 & 4.9 & 90.5 & 8.9 & 0.1 & 93.2 & 42.1 & -5.5 & 97.3 \\
Mart & 32.6 & 5.9 & 85.5 & 20.0 & 3.7 & 88.0 & 56.4 & 1.5 & 87.7 \\
Nisan & 23.9 & 9.2 & 84.3 & 56.9 & 7.2 & 91.0 & 22.1 & 12.0 & 72.6 \\
Mayıs & 20.7 & 15.2 & 70.4 & 145.8 & 0.5 & 87.7 & 80.9 & 14.4 & 83.3 \\
Haziran & 79.0 & 18.1 & 82.8 & 9.4 & 16.6 & 84.6 & 0 & 20.0 & 71.6 \\
Temmuz & 7.4 & 22.0 & 75.4 & 8.5 & 21.6 & 70.8 & 5.5 & 22.8 & 68.1 \\
Ağustos & 0.9 & 24.4 & 66.2 & 0 & 20.0 & 73.5 & 3.5 & 20.8 & 65.1 \\
Eylül & 22.5 & 18.2 & 75.8 & 2.1 & 17.4 & 68.5 & 0 & 18.7 & 66.1 \\
Ekim & 77.1 & 10.0 & 92.5 & 57.9 & 8.5 & 83.6 & 16.1 & 14.2 & 78.1 \\
Kasım & 7.5 & 9.3 & 81.0 & 0 & 0.8 & 86.8 & 14.5 & 7.3 & 92.3 \\
Aralık & 60.4 & 4.2 & 94.1 & 46.1 & 0.9 & 92.1 & 73.2 & 2.2 & 95.1 \\
\hline Toplam & 410.6 & & & 382.2 & & & 372.3 & & \\
\hline Ortalama & & 11.9 & 82.8 & & 8.1 & 84.7 & & 11.0 & 81.2 \\
\hline
\end{tabular}

*Geçit Kuşağı Tarımsal Araştırma Enstitüsü Meteoroloji İstasyonu

* Transitional Zone Agricultural Research Institute Meteorology Station 
Çizelge 2. Plantasyonların kurulduğu yerin toprak analiz sonuçları

Table 2. Soil analysis results of plantations

\begin{tabular}{lccccccc}
\hline $\begin{array}{l}\text { Toprak } \\
\text { Yapısı }\end{array}$ & $\begin{array}{c}\text { Doymuşluk } \\
(\%)\end{array}$ & $\begin{array}{c}\mathrm{pH} \\
\text { (doymuş } \\
\text { toprakta) }\end{array}$ & $\begin{array}{c}\text { Toplam } \\
\text { Tuz } \\
(\%)\end{array}$ & $\begin{array}{c}\text { Kireç } \\
\left(\mathrm{CaCO}_{3}\right) \\
(\%)\end{array}$ & $\begin{array}{c}\text { Organik } \\
\text { Madde } \\
(\%)\end{array}$ & $\begin{array}{c}\text { Alınabilir } \\
\text { Fosfor } \\
\left(\mathrm{kg} \mathrm{P}_{2} \mathrm{O}_{5} / \mathrm{da}\right)\end{array}$ & $\begin{array}{c}\text { Alınabilir } \\
\text { Potasyum } \\
\left(\mathrm{kg} \mathrm{K} \mathrm{K}_{2} \mathrm{O} / \mathrm{da}\right)\end{array}$ \\
\hline Killi & 80 & 7.7 & 0.153 & 6.6 & 1.28 & 13.0 & 199.5 \\
\hline $\begin{array}{l}\text { *Geçit Kuşağı Tarımsal Araştırma Enstitüsü Toprak Su Laboratuarı } \\
\text { * Transitional Zone Agricultural Research Institute Soil and Water Laboratories }\end{array}$
\end{tabular}

* Transitional Zone Agricultural Research Institute Soil and Water Laboratories

Çizelge 3. Çalışılan otlak ayrığı populasyonlarına ait durak bilgileri

Table 3. Information about locations where wheatgrass populations are collected.

\begin{tabular}{|c|c|c|c|c|}
\hline $\begin{array}{c}\text { Populasyon } \\
\text { No }\end{array}$ & $\begin{array}{l}\text { Toplama } \\
\text { Yapılan İl }\end{array}$ & $\begin{array}{c}\text { Toplama } \\
\text { Yapılan İlçe }\end{array}$ & $\begin{array}{c}\text { Toplama } \\
\text { Yapılan Yöre }\end{array}$ & Yükseklik \\
\hline AC 1 & Eskişehir & Alpu & Alpu Mihalıçcık arası yol kenarında & $895 \mathrm{~m}$ \\
\hline AC 2 & Eskişehir & Merkez & Ağapınar Mezarlığı & $784 \mathrm{~m}$ \\
\hline AC 3 & Eskişehir & Alpu & Alpu'dan Mihalıçcıka çıkan yol & $841 \mathrm{~m}$ \\
\hline AC 4 & Eskişehir & Han & Gökçekuyu Köyü & $1110 \mathrm{~m}$ \\
\hline AC 5 & Eskişehir & Alpu & Alpu Mihalıçcık arası yol kenarında & $895 \mathrm{~m}$ \\
\hline AC 6 & Eskişehir & Merkez & Ağapınar Mezarlığı & $784 \mathrm{~m}$ \\
\hline $\mathrm{AC} 7$ & Eskişehir & Seyitgazi & Seyitgazi Türbesi & $1022 \mathrm{~m}$ \\
\hline AC 8 & Eskişehir & Seyitgazi & llçe Mezarlığı & $1009 \mathrm{~m}$ \\
\hline AC 9 & Eskişehir & Han & Gökcekuyu Köyü & $1110 \mathrm{~m}$ \\
\hline$A C 10$ & Eskişehir & Çifteler & Körhasan Köyü & $859 \mathrm{~m}$ \\
\hline AC 11 & Eskişehir & Alpu & Alpu Mihalıçcık arası yol kenarında & $895 \mathrm{~m}$ \\
\hline AC 12 & Eskişehir & Seyitgazi & Bardakçı Köyü & $1036 \mathrm{~m}$ \\
\hline AC 13 & Eskişehir & Han & Merkez & $1224 \mathrm{~m}$ \\
\hline AC 14 & Eskişehir & Seyitgazi & Bardakçı Köyü & $1036 \mathrm{~m}$ \\
\hline AC 15 & Eskişehir & Merkez & Yahnikapan Köyüne 3 km & $908 \mathrm{~m}$ \\
\hline AC 16 & Eskişehir & Merkez & Ağapınar Mezarlığı & $784 \mathrm{~m}$ \\
\hline AC 17 & Eskişehir & Merkez & Ağapınar Mezarlığı & $784 \mathrm{~m}$ \\
\hline AC 81 & Eskişehir & Mihalıçcık & Mihalıç.-Sazaka arası & $782 \mathrm{~m}$ \\
\hline AC 82 & Eskişehir & Mahmudiye & Yeniköy & $915 \mathrm{~m}$ \\
\hline$A C 83$ & Eskişehir & Alpu & Bağduz Köyü & $832 \mathrm{~m}$ \\
\hline AC 84 & Eskişehir & Seyitgazi & Yeşiltepe Köyü & $1032 \mathrm{~m}$ \\
\hline AC 85 & Eskişehir & Merkez & Akçayır & $960 \mathrm{~m}$ \\
\hline AC 86 & Eskişehir & Tepebaşı & A. Danişment & $893 \mathrm{~m}$ \\
\hline AC 87 & Eskişehir & Kırka & Merkez & $1047 \mathrm{~m}$ \\
\hline AC 88 & Eskişehir & Merkez & Nemli & $952 \mathrm{~m}$ \\
\hline AC 89 & Eskişehir & Odunpazarı & Sevinç Mahallesi & $780 \mathrm{~m}$ \\
\hline$A C 90$ & Eskişehir & Sivrihisar & İbiseydi Köyü & $1075 \mathrm{~m}$ \\
\hline AC 91 & Eskişehir & Çifteler & Belpınar Köyü & $961 \mathrm{~m}$ \\
\hline AC 92 & Eskişehir & Günyüzü & Beyyayla Köyü & $954 \mathrm{~m}$ \\
\hline AC 93 & Eskişehir & Kanlıpınar & Kanlıpınar Rampası & $750 \mathrm{~m}$ \\
\hline AC 94 & Eskişehir & Aşağıkepen & Mezarlık & $842 \mathrm{~m}$ \\
\hline AC 95 & Eskişehir & Çifteler & Saithalimpaşa & $870 \mathrm{~m}$ \\
\hline AC 96 & Eskişehir & Çifteler & Ahiler & $807 \mathrm{~m}$ \\
\hline AC 97 & Eskişehir & Kaymaz & İkipınar Köyü & $967 \mathrm{~m}$ \\
\hline AC 98 & Eskişehir & Merkez & Y. Söğütönü & $883 \mathrm{~m}$ \\
\hline AC 99 & Eskişehir & Alpu & Çukurhisar & $798 \mathrm{~m}$ \\
\hline AC 100 & Eskişehir & Sivrihisar & İbiseydi Köyü & $1075 \mathrm{~m}$ \\
\hline AC 122 & Eskişehir & Seyitgazi & Taşlık Köyü & $1072 \mathrm{~m}$ \\
\hline
\end{tabular}

Toplama sırasında koordinatlar, yükseklik, bölge ya da yöre adı ile en yakın yerleşim birimine uzaklık gibi bilgiler kaydedilmiştir. Çalışılan populasyonlara ait durak bilgilerinin bazıları aşağıdadır (Çizelge 3).
Toplanan tohumlar üçe bölünmüş ve bir kısmı Izmir ve Ankara'daki gen bankalarına durak bilgileri ile birlikte gönderilmiştir. Bir kısmı da Geçit Kuşağı Tarımsal Araştırma Enstitüsü'nde muhafaza edilen tek bitkiler, ayrı ayrı viyollerde 


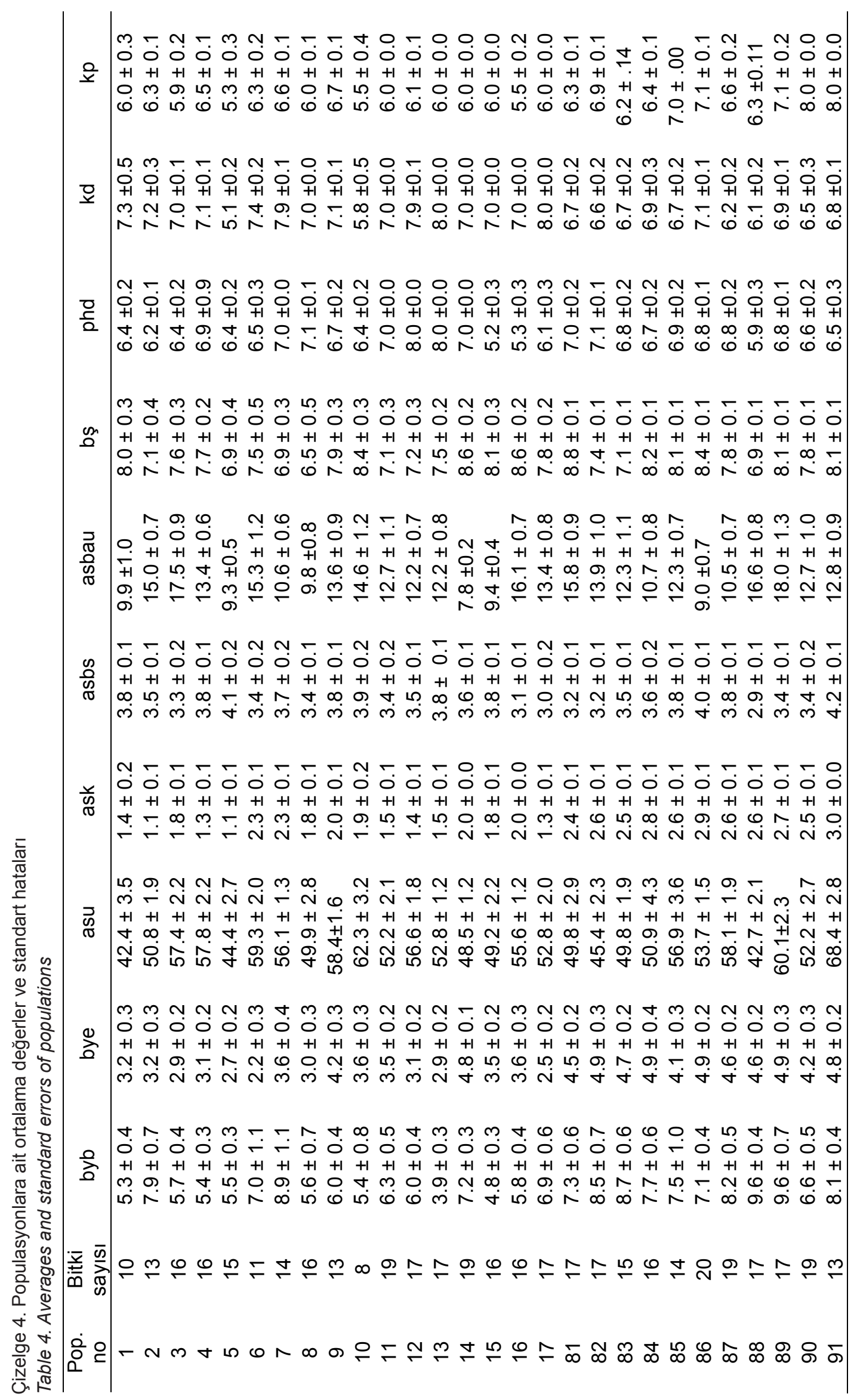



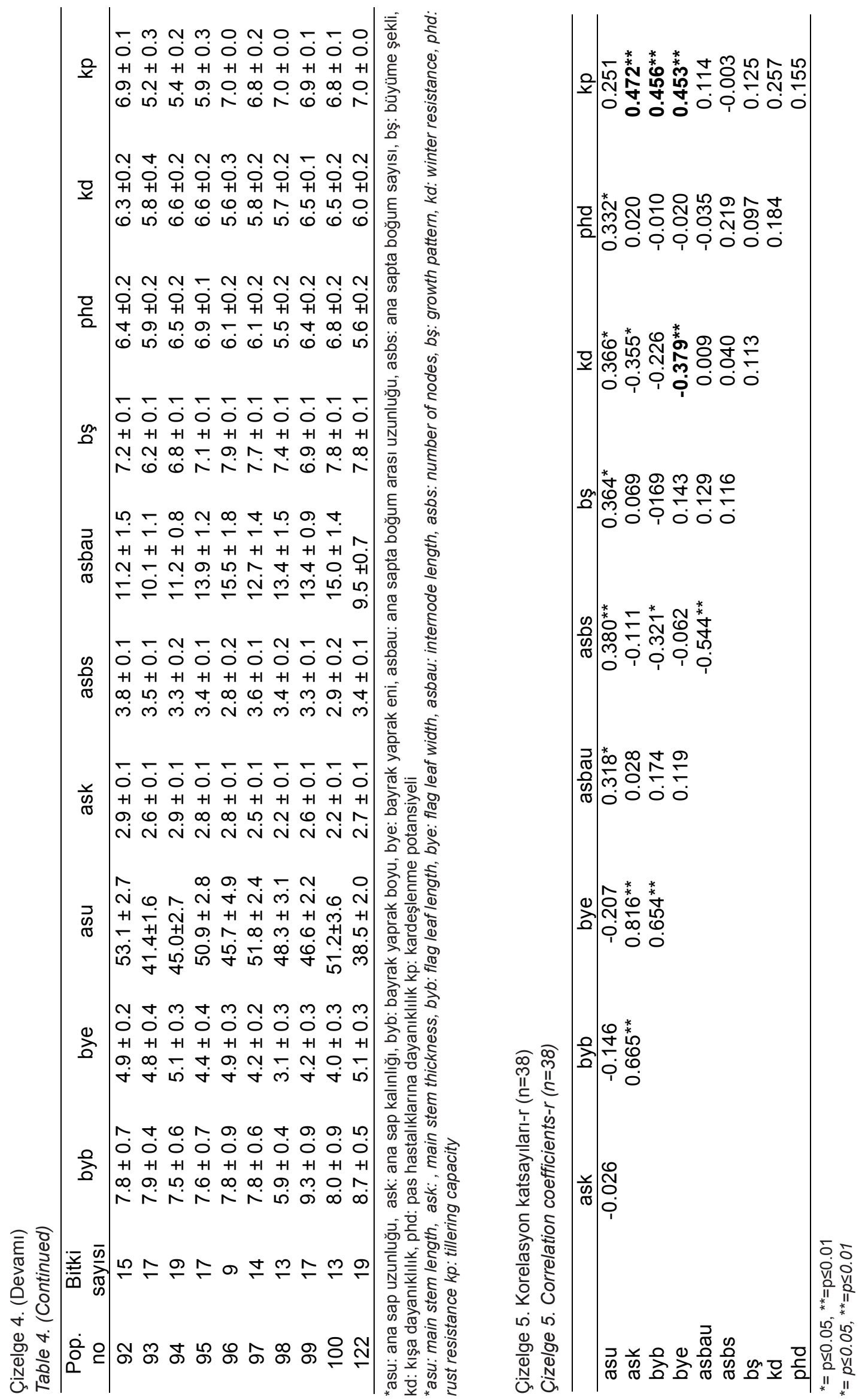
sera koşullarında fide haline getirildikten sonra 2011 yılı Nisan ayında Enstitü merkez arazisinde $50 \mathrm{~cm}$ ocak arası mesafe ile 20'şerli olarak dikilmişlerdir. Başlangıçta her biri 20 bitki içeren populasyonlarda kış ve hastalık gibi sebeplerle bazı bitkiler kaybedilmiştir. Bu doğal populasyonlar 2012 yılında ana sap uzunluğu $(\mathrm{cm})$, ana sap kalınlığı $(\mathrm{mm})$, bayrak yaprak boyu $(\mathrm{cm})$, bayrak yaprak eni $(\mathrm{mm})$, ana sapta boğum arası uzunluğu $(\mathrm{cm})$, ana sapta boğum sayısı, büyüme şekli (1 yatık-9 dik), kışa dayanıkııık (1 hassas-9 dayanıklı), pas hastalıklarına dayanıklıık (1 hassas-9 dayanıkı) ve kardeşlenme potansiyeli ( 1 çok az-9 çok fazla) gözlem ve ölçümlere tabi tutulmuştur (Açıkgöz 1982; Tekeli 1982; Anonim 2001). Islah amaçlı seçimlerde önem taşıyan bu özellikler istatistik analize tabi tutularak populasyonların ortalama değerleri ve standart hataları belirlenmiştir (Çizelge 4). Daha sonra korelasyon analizi yapılarak özellikle kardeşlenme potansiyeli üzerinde diğer parametrelerin etkisi değerlendirilmiştir (Çizelge 5).

\section{Bulgular ve Tartışma}

Toplam 38 otlak ayrığı populasyonuna ait (başlangıçta 20 olan her bir populasyondaki bitki sayısı kış ve hastalık gibi nedenlerle bazılarında azalmıştır) incelenen parametrelerin ortalama değerleri ile bunların standart hataları aşağıda verilmiştir. Populasyon ortalama değerleri ana sap uzunluğunda $38.5 \mathrm{~cm}-68.4 \mathrm{~cm}$, ana sap kalınlığında $1.1 \mathrm{~mm}-3.0 \mathrm{~mm}$, bayrak yaprak boyu $3.9 \mathrm{~cm}-9.6 \mathrm{~cm}$, bayrak yaprak eni $2.2 \mathrm{~mm}-5.1$ $\mathrm{mm}$, ana saptaki boğum arası uzunluğu $7.8 \mathrm{~cm}$ $18 \mathrm{~cm}$, ana saptaki boğum sayısı 2.9 adet- 4.2 adet, büyüme şekli 6.2-8.8, kışa dayanıklılık 5.18.0 ve kardeşlenme potansiyeli 5.2-8.0 arasında değişiklik göstermiş̧tir (Çizelge 4).

Ölçülen ve gözlemlenen tüm parametrelere uygulanan korelasyon analizi sonucunda suni mera tesisi ve üstten tohumlama çalışmaları için önemli özelliklerden olan kardeşlenme potansiyeli ile ana sap kalınlığı, bayrak yaprak eni ve bayrak yaprak boyu arasında çok önemli ve olumlu ilişkiler $\left(r=0.472^{* *}, r=0.456^{* *}\right.$ ve $\left.r=0.453^{* \star}\right)$ dikkat çekmiştir. Açıkgöz (1982), otlak ayrığında toplam kardeş sayısı ile kuru ot verimi arasında önemli ve olumlu ilişki $\left(r=0.420^{* *}\right)$ saptamıştır. Karakurt ve Ekiz (2000) ise, toplam kardeş sayısı ile kuru ot verimi arasında olumlu, ancak önemsiz bir ilişki tespit etmişlerdir $(r=0.703)$. Çalışmamızda Orta Anadolu şartları için önemli bir özellik olan kışa dayanıkılık ile bayrak yaprak eni arasındaki çok önemli ve negatif ilişki de $\left(r=0.379^{* \star}\right)$ dikkat çekmiş̧tir (Çizelge 5).

\section{Sonuç}

Toplama ve tanımlama çalışmaları ile elde edilen materyal ve bilgi Geçit Kuşağı Tarımsal Araştırma Enstitüsü tarafından yürütülmekte olan mera tipi otlak ayrığı ıslah çalışmalarında kullanımaktadır.

Geliştirilmesi planlanan çeşitler kurak meralarımızda yürütülen ıslah çalışmaları bakımından önem taşımaktadır.

\section{Kaynaklar}

Açıkgöz E., 1982. Adi otlak ayrığında (Agropyron cristatum L.) bazı morfolojik ve tarımsal özellikleri ile çiçek biyolojisi üzerinde araştırmalar. Ankara Üniv. Zir. Fak. Yay. No:802, Ankara, $62 \mathrm{~s}$

Alan N., 1986. Bitki Genetik Kaynakları El Kitabı, Ege Bölge Zir. Ar. Ens. Yayınları, No: 70

Anonim 2001. Tarımsal değerleri ölçme denemeleri teknik talimatı, buğdaygil yembitkileri. TC. Tar. ve Köy. Bak. Kor. ve Kont. Gen. Müd. Toh. Tes. Ve Sertifikasyon Mer. Müd

Karakurt E. ve Ekiz H., 2000. Bazı buğdaygil yem bitkilerinde kuru ot verimi ile bazı verim komponentleri arasındaki ilişkilerin path analizi ile değerlendirilmesi. Tarla Bitkileri Merkez Araştırma Enstitüsü Dergisi, Cilt 9, Sayı 1-2

Kavuncu O., Çiftçi Y.C. ve Tekeli A.S., 1985. Mürdümük (Lathyrus sativus L.) ekotiplerinde verimle çeşitli verim öğeleri arasındaki sebepsonuç iliş̧ilerinin path analizi ile araştıııması. Doğa Bilimleri Dergisi, D2.9.2

Oral N. ve Açıkgöz E., 2002. Çim Alanlar İçin Tohum Karışımları. TMMOB Ziraat Mühendisleri Odası Bursa Şubesi Başkanlığı Yayınları: 1. Bursa

Serin Y., Gökkuş A., Tan M., Koç A. ve Çomaklı B., 1998. Sun'i çayır tesisinde kullanılabilecek uygun yem bitkileri ve karışımlarının belirlenmesi. Turk. Jour. of Agr. and Forest., 22: $13-20$

Tekeli S., 1982. Farklı biçim yüksekliklerinin kılçıksız brom (Bromus inermis Leyss.) ve mavi ayrık (Agropyron intermedium (Host) Beauv.)'ta kök ve toprak üstü organlarının gelişmeleri üzerine etkileri. Ankara Üniv. Zir. Fak., Tarla Bitkileri Yetiştirme ve Islahı Bölümü, Ankara 